\title{
Internal wave-mediated shading causes frequent vertical migrations in fishes
}

\author{
Stein Kaartvedt ${ }^{1,2, *}$, Thor A. Klevjer ${ }^{1,2}$, Dag L. Aksnes $^{3}$ \\ ${ }^{1}$ King Abdullah University of Science and Technology, Red Sea Research Center, Thuwal 23955-6900, Saudi Arabia \\ ${ }^{2}$ Department of Biology, University of Oslo, 0316 Oslo, Norway \\ ${ }^{3}$ Department of Biology, University of Bergen, 5020 Bergen, Norway
}

\begin{abstract}
We provide evidence that internal waves cause frequent vertical migrations (FVM) in fishes. Acoustic data from the Benguela Current revealed that pelagic scattering layers of fish below $\sim 140 \mathrm{~m}$ moved in opposite phases to internal waves, ascending $\sim 20 \mathrm{~m}$ towards the wave trough and descending from the wave crest. At the trough, the downward displacement of upper waters and the upward migration of fish created an overlapping zone. Near-bottom fish correspondingly left the benthic boundary zone at the wave trough, ascending into an acoustic scattering layer likely consisting of zooplankton and then descending to the benthic boundary zone at the wave crest. We suggest that this vertical fish migration is a response to fluctuations in light intensity of 3 to 4 orders of magnitude caused by shading from a turbid surface layer that had chlorophyll $a$ values of 3 to $4 \mathrm{mg} \mathrm{m}^{-3}$ and varied in thickness from $\sim 15$ to $50 \mathrm{~m}$ at a temporal scale corresponding to the internal wave period (30 min). This migration frequency thus is much higher than that of the common and widespread light-associated diel vertical migration. Vertical movements affect prey encounters, growth, and survival. We hypothesize that FVM increase the likelihood of prey encounters and the time for safe visual foraging among planktivorous fish, thereby contributing to efficient trophic transfer in major upwelling areas.
\end{abstract}

KEY WORDS: Internal waves - Shading $\cdot$ Antipredation window $\cdot$ Vertical migration $\cdot$ Acoustics written consent of the publisher

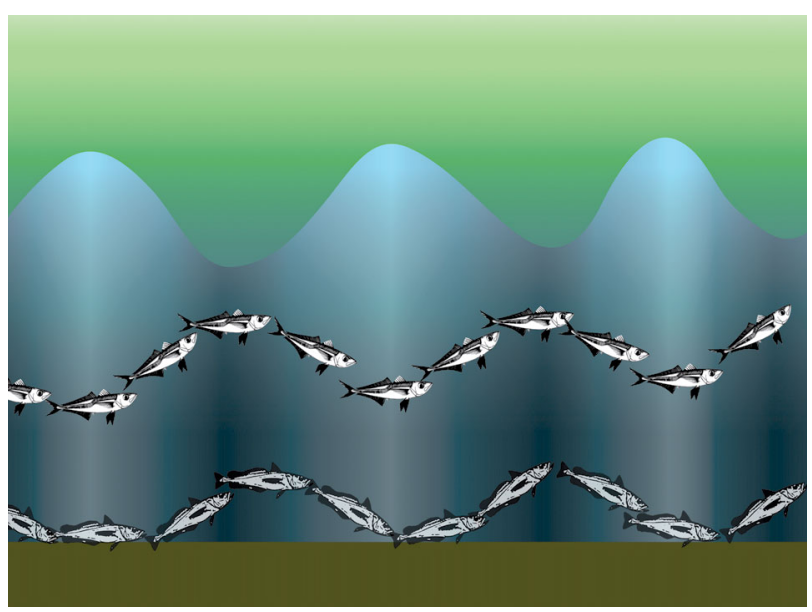

Pelagic and demersal fishes undertake vertical migrations in response to internal waves, as these cause changes in light penetration through the turbid surface layer of the sea.

Illustration: Hege Vestheim

\section{INTRODUCTION}

Internal waves propagating horizontally along isopycnal surfaces are a ubiquitous feature of the oceans. The waves are formed by variable wind stress and the actions of tides and currents on the ocean bottoms and continental margins (Garrett \& Munk 1979). Several effects of internal waves have been described, such as the contribution of mixing to the return flow in the global overturning circulation (Ledwell et al. 2000, Garabato et al. 2004), the 
supply of nutrients to the euphotic zone (Holligan et al. 1985), an increase in light exposure for phytoplankton photosynthesis (Holligan et al. 1985, Lande \& Yentsch 1988), and the shaping of the distribution and concentration of zooplankton (Haury et al. 1979, Lennert-Cody \& Franks 1999, Macias et al. 2010). Here, we report results suggesting that shading by internal wave-mediated variations in the thickness of a turbid surface layer causes frequent vertical migrations (FVM) in fish, similar to the widespread and much studied diel vertical migration (DVM) (Gliwicz 1986, Clark \& Levy 1988, Ringelberg 2010) but with a frequency an order of magnitude higher than DVM.

The fastest way for a pelagic organism to change its environment is to move in the direction with the steepest environmental gradients, normally represented by the depth axis. Such movement has consequences for vital processes, such as prey encounters, growth, and survival. Theoretical (Clark \& Levy 1988, Rosland \& Giske 1994) and observed (Giske \& Aksnes 1992, Baliño \& Aksnes 1993, Scheuerell \& Schindler 2003) evidence suggests that for a planktivorous fish hunting by vision, lightinduced vertical migrations (DVM behaviors) provide an appropriate balance between seeing smaller prey and not being seen by larger predators simply by keeping the ambient light intensity within appropriate limits. On short time scales, the only way for a fish to control the amount of ambient light surrounding it in open water is to move vertically. Because water attenuates light rapidly, such movement is efficient. For example, a $90 \%$ reduction in surface light can be compensated by upward movement of $\sim 45 \mathrm{~m}$ in clear oceanic water $\left(K=0.05 \mathrm{~m}^{-1}\right)$ or $12 \mathrm{~m}$ in murkier coastal water $\left(K=0.2 \mathrm{~m}^{-1}\right.$, where $K$ represents the attenuation of the downwelling irradiance for the wavelengths relevant to the visual system in question). The characteristic dawn and dusk migrations of species exhibiting DVM occur when changes in incoming solar radiance are the largest, but less extensive vertical migrations have been observed during days with variable radiation due to cloudiness (Baliño \& Aksnes 1993, Staby \& Aksnes 2011). Rather than showing variations in incoming solar radiance, the results presented here show upward daytime migrations of fish that are concurrent with a reduction in light intensity of 3 to 4 orders of magnitude in the lower part of the water column. This reduction is caused by shading from a turbid surface layer that varies in thickness on a temporal scale corresponding to the internal wave period (30 $\mathrm{min})$.

\section{MATERIALS AND METHODS}

\section{Study site}

The study took place at a $\sim 160$ to $180 \mathrm{~m}$ deep shelf location $\left(23^{\circ} 30^{\prime} \mathrm{S}, 13^{\circ} 40^{\prime} \mathrm{E}\right)$ in the Benguela Current off Namibia in April 2008, using the Norwegian RV 'G.O. Sars' (Fig. 1). This study site was also used by van der Bank et al. (2011) and is the same as the outer shelf region of the study by Utne-Palm et al. (2010). Both of those studies were conducted during the same survey as ours. The location was west of the most severely hypoxic area in which the bearded goby Sufflogobius bibarbatus appears to thrive and dominate (Utne-Palm et al. 2010), although the oxygen contents were also low in near-bottom water in the study site (see 'Results').

The Benguela Current is one of the main upwelling and fish-producing regions of the world (Ryther 1969, Longhurst \& Pauly 1987). Presently, the most abundant fishes of this upwelling system are the bearded goby Sufflogobius bibarbatus, the horse mackerel Trachurus trachurus capensis, and the hake Merluccius capensis (Utne-Palm et al. 2010).

\section{Acoustic records}

Acoustic records were made with Simrad EK 60 echosounders on each of 5 frequencies $(18,38,70$, 120 , and $200 \mathrm{kHz}$ ). The beam width of the transduc-

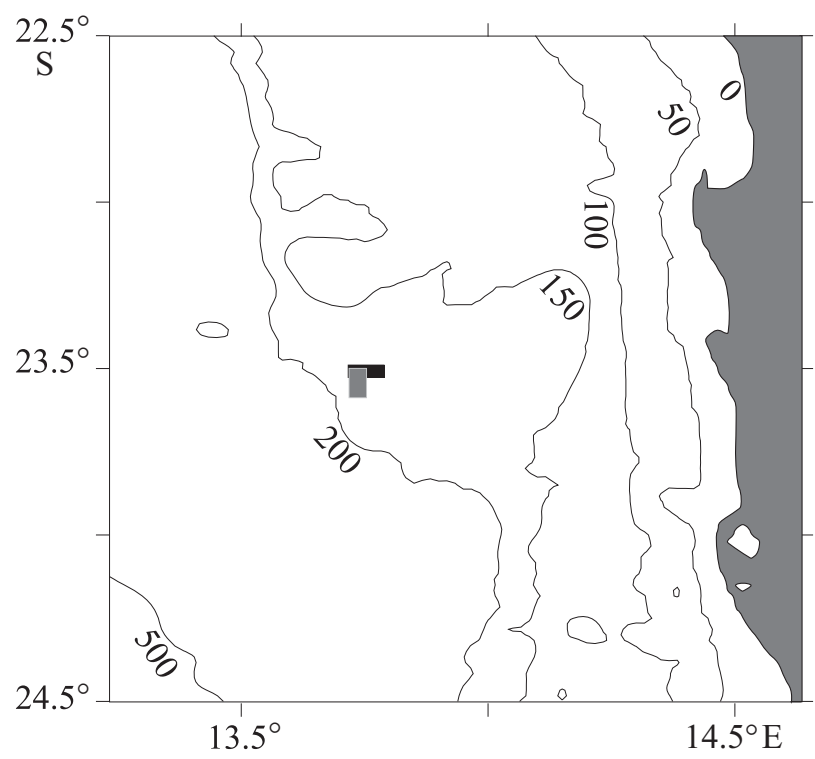

Fig. 1. Study area off the coast of Namibia. All trawl stations were within the region in the grey box, and all acoustic stations were within the black box 
ers was $7^{\circ}$, except for the $18 \mathrm{kHz}$ transducer, which had a beam width of $12^{\circ}$. The echograms were visualized with a customized Java application and Matlab. Identification of acoustic targets was suggested based on trawling (see this section, below) and the detection of separate targets at different acoustic frequencies. Jellyfish form conspicuous acoustic scattering layers in the Benguela current (Brierley et al. 2001) and may be strong targets even at $18 \mathrm{kHz}$ (Kaartvedt et al. 2007), with reduced acoustic backscatter at high frequencies (Graham et al. 2010). Other zooplankton (smaller than jellyfish) normally give increased backscattering with increasing frequency and are only detected at the highest frequency applied in this study (Greenlaw 1979). Fish with swim bladders are strong acoustic targets. From a stationary vessel (used for many of the acoustic records presented here) individual fish can be followed over many 'pings', and are usually distinguished from jellyfish based on their more active vertical swimming behavior. In this study, internal waves were determined acoustically using records of vertically displaced acoustic targets, ascribed to jellyfish. Acoustic records of internal waves and the concurrent responses of fish were made during all 3 of the days (4,5 and 9 April) that the vessel worked at the site for this study (see 'Results').

\section{Hydrography and fluorescence}

Concurrent with acoustic registrations exposing internal waves, we performed repetitive casts with a CTD probe, additionally equipped with an oxygen sensor, fluorometer and light transmissometer. To characterize the internal waves, casts with the CTD were taken continuously while internal waves were simultaneously recorded acoustically. Records were made on both the downcasts and upcasts; in total, 16 profiles were obtained from the water column. Contour plots were produced using the contour function in the R software package ( $\mathrm{R}$ Development Core Team 2011).

\section{Light measurements}

Surface irradiance (photosynthetically active radiation, PAR) was continuously measured by the ship's weather station and stored as $10 \mathrm{~min}$ averages. The light transmission at $660 \mathrm{~nm}$ was recorded by the transmissometer on the CTD. Due to a malfunction of a PAR sensor that was attached to the CTD, the atten- uation coefficient for downwelling irradiance, and thereby the downwelling irradiance, was estimated from observed surface irradiance, and an attenuation coefficient was derived from the in situ fluorescence.

The surface irradiance decreased almost monotonically from $\sim 300$ to $100 \mu \mathrm{mol} \mathrm{m} \mathrm{m}^{-2} \mathrm{~s}^{-1}$ during the repetitive CTD casts (Fig. 2). A linear regression equation was fitted to the $10 \mathrm{~min}$ averages to interpolate the surface irradiance for the respective CTD casts.

To assess the underwater light conditions during the internal waves recorded by the CTD casts, the downwelling irradiance, $E(z, t)$, as a function of depth $(z)$ and time $(t)$ was calculated according to Eq. (1):

$$
E(z, t)=0.5 E(0, t) \prod_{i=1}^{n(z)} \exp \left(-K_{i, t} \Delta z_{i}\right)
$$

where $E(0, t)$ is the observed surface irradiance at time $t$ (Fig. 2). Due to the malfunction of the underwater light sensor, the surface reflectance was not measured. Surface reflectance varies with the angle of the incident light and the surface roughness (Kirk 2011), and a transmittance through the sea surface of $50 \%$ was assumed. The $\Delta z_{i}$ components are the depth layers between the surface and the depth $z$ for which the $E(z, t)$ is calculated, $n(z)$ is the number of depth layers above $z$, and $K_{i, t}$ is the calculated attenuation of downwelling irradiance of the depth layer, $\Delta z$, at time $t$. This attenuation was calculated by assuming the relationship for oceanic Case I waters (Morel 1988):

$$
K_{i, t}=0.121 \mathrm{Chl}_{i, t}^{0.428}
$$

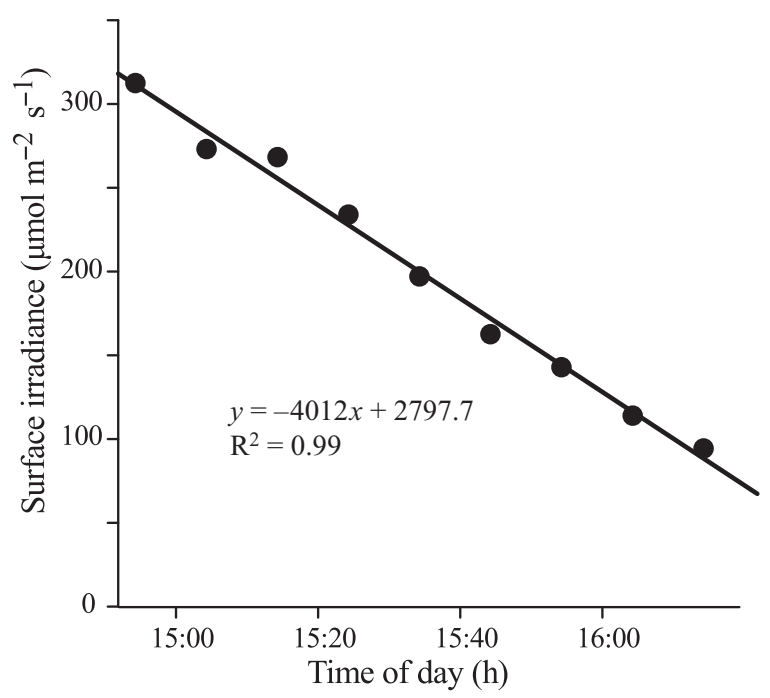

Fig. 2. Surface irradiance (photosynthetically active radiation, PAR, $\mu \mathrm{mol} \mathrm{m} \mathrm{m}^{-2} \mathrm{~s}^{-1}$ ) during the CTD casts on 9 April 2008 (10 min averages). The linear regression equation was fitted to the $10 \mathrm{~min}$ averages to obtain the surface irradiance for the respective CTD casts 
where $\mathrm{Chl}_{i, t}$ is the chlorophyll a (chl a) concentration that was derived from measurements of in situ fluorescence.

The beam attenuation coefficient $(c)$ was calculated from the measured transmission (at $660 \mathrm{~nm}$ ), $T$, according to $C=\ln T / r$, where $r$ is the path length of the light beam $(0.25 \mathrm{~m})$. The values observed in our study were in the same range, 0.4 to $1.4 \mathrm{~m}^{-1}$, as observed by Inthorn et al. (2006) off the Namibian coast. There was a strong relationship $\left(\mathrm{r}^{2}=0.98, \mathrm{n}=\right.$ 4984) between the calculated attenuation of PAR $\left(K_{i, t}\right.$ Eq. 1$)$ and the corresponding observed beam attenuation coefficient $\left(c_{i, t}\right)$ :

$$
K_{i, t}=0.22 c_{i, t}-0.029
$$

\section{Trawling}

Demersal and pelagic trawling was carried out on 4 and 5 April (i.e. days during which the acoustic observations of internal waves were made) to assess the fauna. Pelagic trawling was carried out with a 'macro plankton trawl' with an opening area of $65 \mathrm{~m}^{2}$, too small to capture many fast-swimming fish. The pelagic trawl was equipped with a Multisampler cod-end, permitting depth-stratified sampling (Engås et al. 1997). In total, 7 demersal and 13 pelagic trawl samples were obtained during the day and night. The pelagic tows covered 6 and 7 depth intervals from $\sim 160 \mathrm{~m}$ to $\sim 25 \mathrm{~m}$ in the daylight and darkness, respectively (Table 1).

\section{RESULTS}

\section{Hydrography, fluorescence, and irradiance}

The observations of temperature, fluorescence, and light beam attenuation coefficients revealed that the warm, turbid surface layer varied in thickness by $\sim 35 \mathrm{~m}$ with a period of $\sim 30 \mathrm{~min}$ (Fig. 3). We attribute this variation to the propagation of internal waves. The temporal fluctuations in the observed variables decreased with increasing depth, and the temperature and density in the near-bottom waters barely fluctuated (Fig. 3). More detailed information on the structure and thickness range of the upper mixed layer as well as the consistency in deeper waters is afforded by comparing measurements made during the shallowest crest and deepest trough and by including data on oxygen content (Fig. 4). This comparison reveals similar, although not identical, patterns for the measured parameters. Chl $a$ and beam attenuation varied in concert in the upper $\sim 80 \mathrm{~m}$, with the thickness of the high-chl a/high-beamattenuation layer varying between $\sim 15$ and $50 \mathrm{~m}$. There was a subsequent slight increase in the beam attenuation in the near-bottom waters, independent of the phase of the wave. The effect of the wave on temperature and density was recorded to just below $100 \mathrm{~m}$. The deepest wave signal from the CTD casts was recorded in the oxygen content, which appeared to fluctuate down to $\sim 125 \mathrm{~m}$, where values were $\sim 0.7 \mathrm{ml} \mathrm{O}_{2} \mathrm{l}^{-1}$ irrespective of wave phase. The oxygen concentration subsequently decreased towards the bottom, reaching a minimum of $0.4 \mathrm{ml} \mathrm{O}_{2} \mathrm{l}^{-1}$ (Fig. 4).

The periodic fluctuation in the thickness of the less transparent surface layer caused strong fluctuations in the calculated downwelling irradiance throughout the water column and consequently shading below (Fig. 3). The estimated near-bottom irradiance levels varied by 3 to 4 orders of magnitude between wave crests and troughs, creating short-period 'day-night' cycles corresponding to that of the wave period ( $\sim 30 \mathrm{~min})$.

\section{Acoustic data}

Acoustic records made concurrently with the CTD casts revealed that the vertical distribution of the acoustic backscatter in the upper part of the water column (largely ascribed to jellyfish, see 'Discussion') fluctuated in phase with the internal waves (Fig. 3). Acoustic targets in the near-bottom water, ascribed to fish, were disturbed by the CTD casts, indicating avoi-

Table 1. Summary information from 13 pelagic and 7 bottom trawl catches. Results are given as the percentage of weight of the total catch, and for fish, the average size is also given. Sampling depths (measured at the trawl headline) for pelagic tows

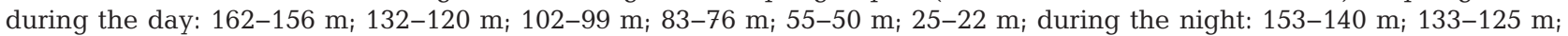
$107-100 \mathrm{~m}_{;}$97-93 m; 90-70 m; 51-45 m; 27-26 m

\begin{tabular}{|ccccccccc|}
\hline & \multicolumn{2}{c}{ Merluccius } & \multicolumn{2}{c|}{ Trachurus } & $\begin{array}{c}\text { Aequorea } \\
\text { Weight }(\%)\end{array}$ & $\begin{array}{c}\text { Chrysaora } \\
\text { Weight (\%) }\end{array}$ & $\begin{array}{c}\text { Other } \\
\text { Weight (\%) }\end{array}$ & $\begin{array}{c}\text { Total catch } \\
\left(\mathrm{g} \text { per } 1000 \mathrm{~m}^{3}\right)\end{array}$ \\
\hline Bottom & 17.5 & 184 & 26.7 & 252 & 34.5 & 19.9 & 1.5 & 20771 \\
Pelagic & 5.4 & 164 & 0.1 & 31 & 53.7 & 37.4 & 3.4 & 109 \\
\hline
\end{tabular}




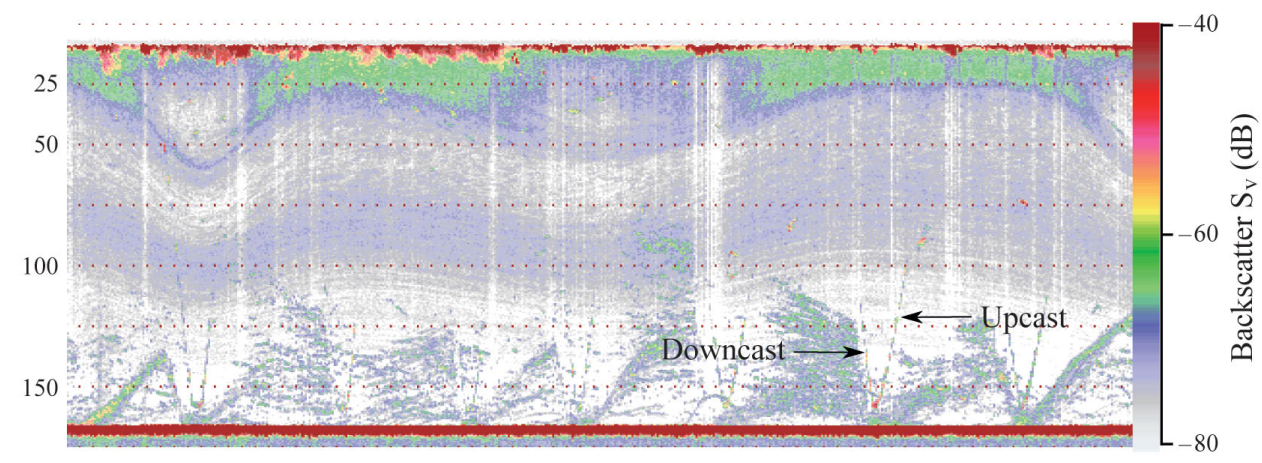

Fig. 3. Internal waves at the Namibian shelf. Observations of temperature, density (isolines [white] for 1026.7 and $1027.2 \mathrm{~kg}$ $\mathrm{m}^{-3}$ superimposed on the temperature plot), fluorescence, beam attenuation at $660 \mathrm{~nm}$, and the calculated downwelling irradiance (PAR) during cycles of internal waves. The depth-time distribution is based on 16 repetitive sampling probe casts on 9 April 2008. The first panel shows acoustic records (volume backscatter; $\mathrm{S}_{\mathrm{v}}$ ) at $120 \mathrm{kHz}$ made during these measurements depicting both the internal waves and acoustic tracks of the sampling probe
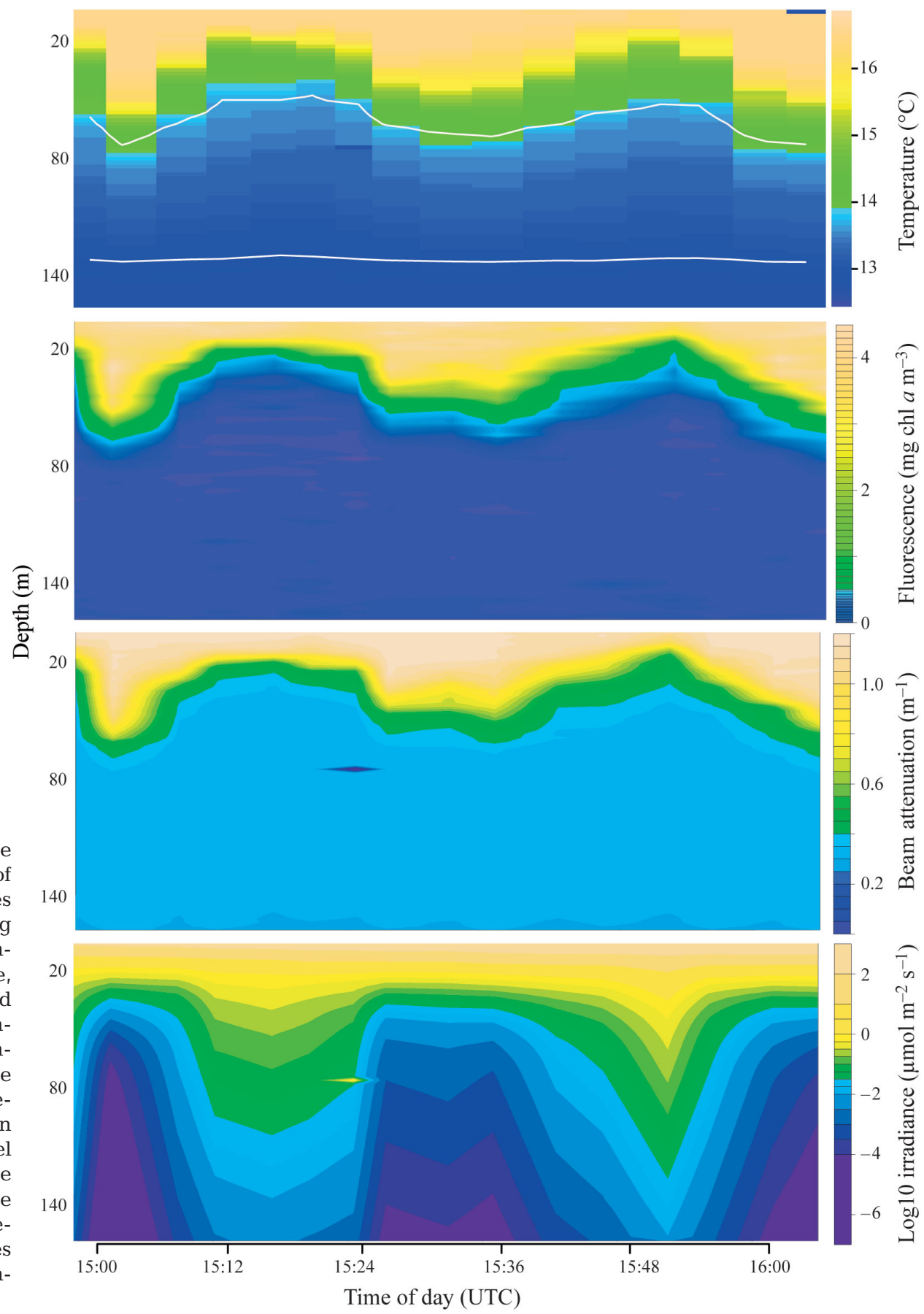


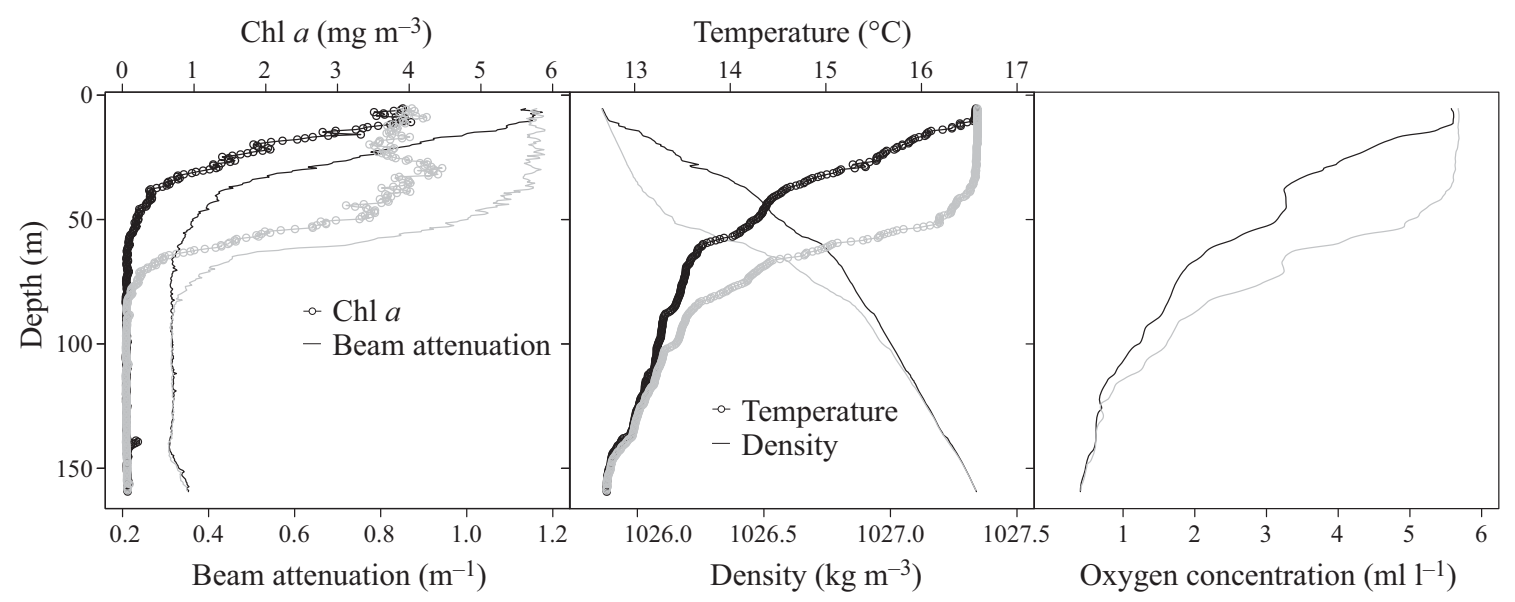

Fig. 4. Vertical distribution of $\mathrm{chl} a$, beam attenuation, density, temperature and oxygen as measured during the shallowest crest (black) and deepest trough (gray) of internal waves

dance behavior (Fig. 3). Undisturbed acoustic registrations, however, were obtained on other days and independent of CTD casts both when the vessel was stationary and moving (Fig. 5). These registrations revealed that both pelagic and semidemersal fish (most likely horse mackerel and hake, see 'Discussion') were moving vertically in opposite phase to the waves (Fig. 5). These movements of fish reflected active swimming because there was no evidence in the CTD casts or echograms of physical vertical displacement opposite to the wave (Figs. $3 \& 4$ ). Accordingly, the co-occurring, near-bottom acoustic backscatter at $200 \mathrm{kHz}$ ascribed to zooplankton exhibited no evident vertical movements as fish entered this layer from the bottom in opposite phase of the wave (Fig. 5). Furthermore, the ascending sound scattering layer of pelagic fish intercepted the lower fringe of the concurrently downwelling plankton backscatter (Fig. 6). In the example presented in Fig. 6, fish were found to ascend to $120 \mathrm{~m}$, while acoustic traces ascribed to downwelling jellyfish were simultaneously recorded down to $\sim 135 \mathrm{~m}$. Thus, as the high light-attenuating surface waters were thickening and a dusk-like situation arose below, fish ascended. When surface waters were narrowing and more light penetrated to the waters below, fish descended. There was no systematic fluctuation in the surface light during these registrations (Fig. 5).

\section{Trawl catches}

Catches were dominated by 4 species: the jellyfishes Aequorea forskalea and Chrysaora hysoscella, the hake Merluccius capensis and the horse mackerel Trachurus trachurus capensis (Table 1). We avoided trawling in the densest 'jellyfish layers' because, on previous cruises, we had collected several tons of jellyfish in these acoustic structures, thereby rupturing the trawl. Even so, jellyfish made up $91 \%$ of the pelagic catches in terms of biomass.

\section{DISCUSSION}

The present study revealed a strong relationship between internal waves and the behavior of fish in the Benguela Current. As early as the 1970s, echograms of plankton layers revealed the signature of extensive internal waves in the Benguela upwelling system (Longhurst \& Pauly 1987), while the concurrent response of fish described here is, to our knowledge, a novel finding. Jellyfish likely made up the bulk of the plankton echoes depicting the internal waves. This was suggested by the catches of jellyfish in the pelagic trawl and the clear acoustic signals even at low frequencies, as large jellyfish can still be recorded at $18 \mathrm{kHz}$ (Kaartvedt et al. 2007). Also, Brierley et al. (2001) identified corresponding scattering layers in the Benguela Current off $\mathrm{Na}$ mibia as consisting of jellyfish. We ascribe the acoustic signatures of fish to hake and horse mackerel, based on the trawl catches and knowledge of the fish fauna from previous studies. Horse mackerel in the Benguela upwelling system form daytime acoustic scattering layers near the seabed or sometimes in mid-column waters, where they forage on deep-water plankton (Pillar \& Barange 1998). Juvenile hake normally reside in near-bottom waters and ascend into the water column during feeding migrations under the cover of darkness at night (Pillar \& Barange 1995, 1997). 

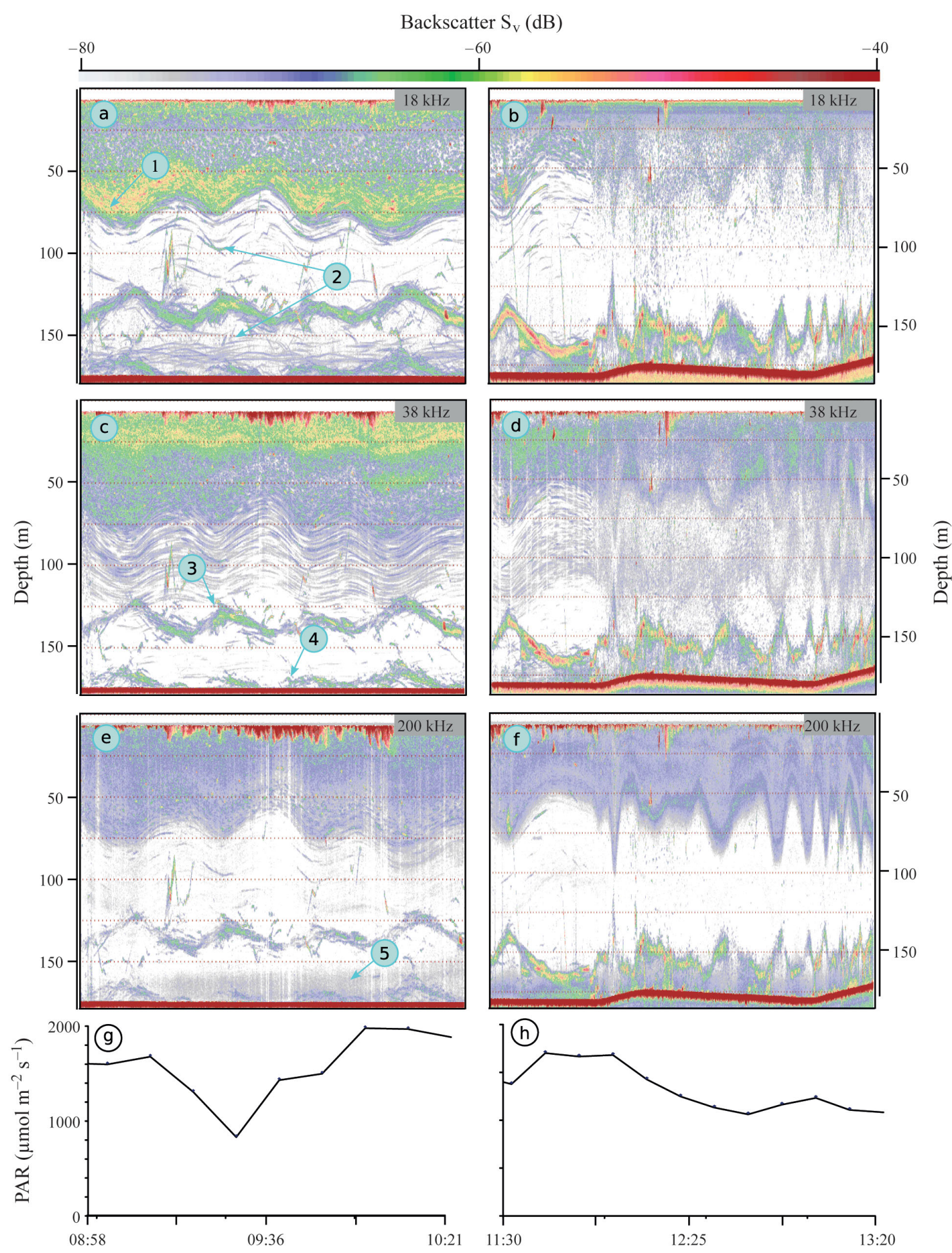

Time (h)

Fig. 5. Response of fish to internal waves. Echograms from (a,c,e) 4 and (b,d,f) 5 April 2008 at (a,b) 18 kHz, (c,d) 38 kHz, and $(\mathrm{e}, \mathrm{f}) 200 \mathrm{kHz}$; frequencies were selected for the optimal display of fauna. Color scale: volume backscatter $\left(\mathrm{S}_{\mathrm{v}}\right)$ values $(\mathrm{dB})$. The vessel was stationary on 4 April and during the first wave cycle on 5 April, giving those data a more extended appearance than the subsequent waves, which were recorded when the vessel was moving (increasing speed from 2 to $10 \mathrm{knots}$ ). Acoustic targets are identified as: (1) assemblages of jellyfish being displaced by internal waves; (2) individual jellyfish reflecting internal waves in mid-waters and little vertical displacement in deep waters; (3) an acoustic scattering layer of fish (likely horse mackerel) swimming vertically in opposite phase with the internal waves; (4) fish (likely juvenile hake) leaving and returning to the bottom in opposite phase with the internal waves; and (5) unidentified assemblages of zooplankton, which are only displayed at high acoustic frequency. The acoustic backscatter of zooplankton shows no vertical movement, suggesting little physical displacement in near-bottom waters. $(g, h)$ Surface light during the acoustic records. PAR: photosynthetically active radiation 


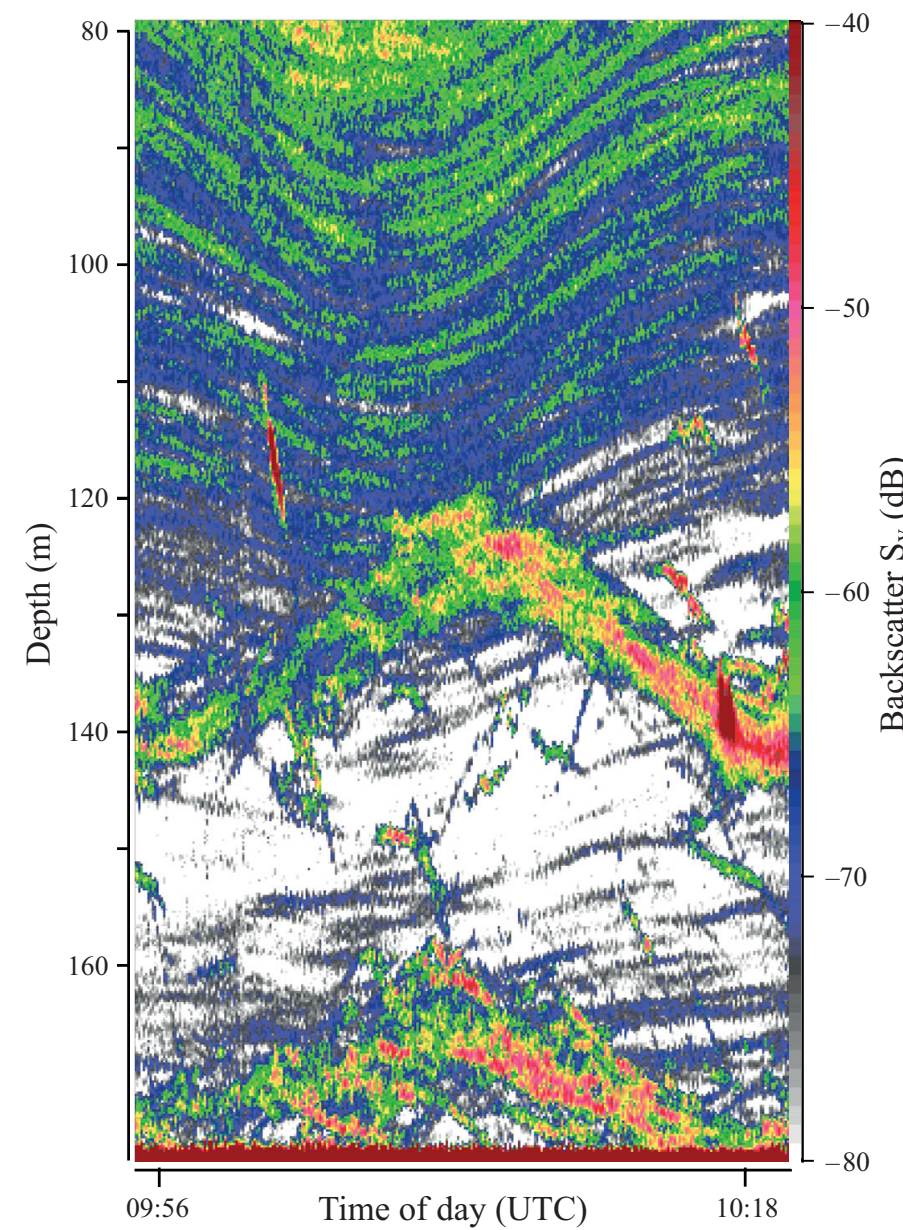

Fig. 6. Acoustic backscatter data, showing the interception of the downwelling plankton scattering layer and ascending fish (excerpt from Fig. 5)

We suggest that the observed vertical movements of fish are light-induced migrations initiated by the shading effect caused by the periodic displacement of the high light-attenuating surface layer by the action of the internal wave. Migrations due to variations in light are well known, although at other time scales. The best documented example is DVM, such as the DVM of hake and horse mackerel in the Benguela Current (Axelsen et al. 2004, Pillar \& Barange 1995), but temporal fish migrations have also been observed for light variations related to variable cloudiness (Baliño \& Aksnes 1993, Staby \& Aksnes 2011). Similarly, spatial variations in the fish depth distribution have been associated with cooccurring variations in shading caused by chlorophyll (Kaartvedt et al. 1996) and related to turbidity from resuspended sediments (Sassa et al. 2010). We reject the alternative explanation that the fish movements that are in opposite phase with the wave were caused by physical displacement by a near-bottom Type II wave in the opposite phase (Shroyer et al. 2010). The density in the near-bottom waters barely fluctuated, and the ascending acoustic scattering layer of pelagic fish intercepted the lower fringe of the concurrent downwelling sound scatter of plankton (jellyfish) (Fig. 6). Furthermore, individual jellyfish $(18 \mathrm{kHz})$ in near-bottom waters remained vertically stationary throughout the wave cycles, in contrast to the jellyfish found in shallower waters. Other near-bottom records, which also were vertically stationary, only became visible at $200 \mathrm{kHz}$ and therefore likely arise from assemblages of zooplankton (Greenlaw 1979). Such records were patchily distributed and sometimes lifted slightly from the bottom with an acoustic void below (data not shown). As a consequence, they cannot be ascribed to range-dependent noise at high frequency. Moreover, such voids also suggest that this backscatter was not caused by particles associated with the near-bottom nepheloid layer (Inthorn et al. 2006).

The antipredation window hypothesis (Clark \& Levy 1988, Scheuerell \& Schindler 2003) proposes that a planktivorous fish that hunts by vision should occupy a depth interval of intermediate light levels, i.e. a window where visual detection of plankton prey is achievable but where the chance of being spotted by a larger visual predator is sufficiently low. Two superior daily feeding periods occur for brief intervals at dawn and dusk when this intermediate light-level window passes through the water column, giving rise to the DVM pattern. Our results suggest that the number of such superior feeding periods could increase by more than 10-fold in areas where active internal waves are coupled with turbid upper layers, compared with diel variations alone. However, the rapid light fluctuations were stronger than the compensatory behavior of the fishes, and estimates of the vertical displacement of isolumes suggested that the light experienced by the fish spanned $\sim 2$ orders of magnitude.

The shading effect depends on both the chl a level (turbidity) of the upper water mass and the thickness of the turbid layer. In our study, these factors were 3 to $4 \mathrm{mg} \mathrm{chl} \mathrm{a} \mathrm{m}^{-3}$ and $\sim 15$ to $\sim 50 \mathrm{~m}$, respectively. The calculated shading effect of the internal wave during the study period indicated that there was a reduction in irradiance close to the bottom by 3 to 4 orders of magnitude, yet the shading effect from internal waves might be stronger than shown here. Our results suggest a $K$ of $\sim 0.21 \mathrm{~m}^{-1}$ in the turbid layer. A $1 \%$ light level at $11 \mathrm{~m}$ depth, corresponding to a $K$ value of $0.42 \mathrm{~m}^{-1}$, has been reported (Estrada \& 

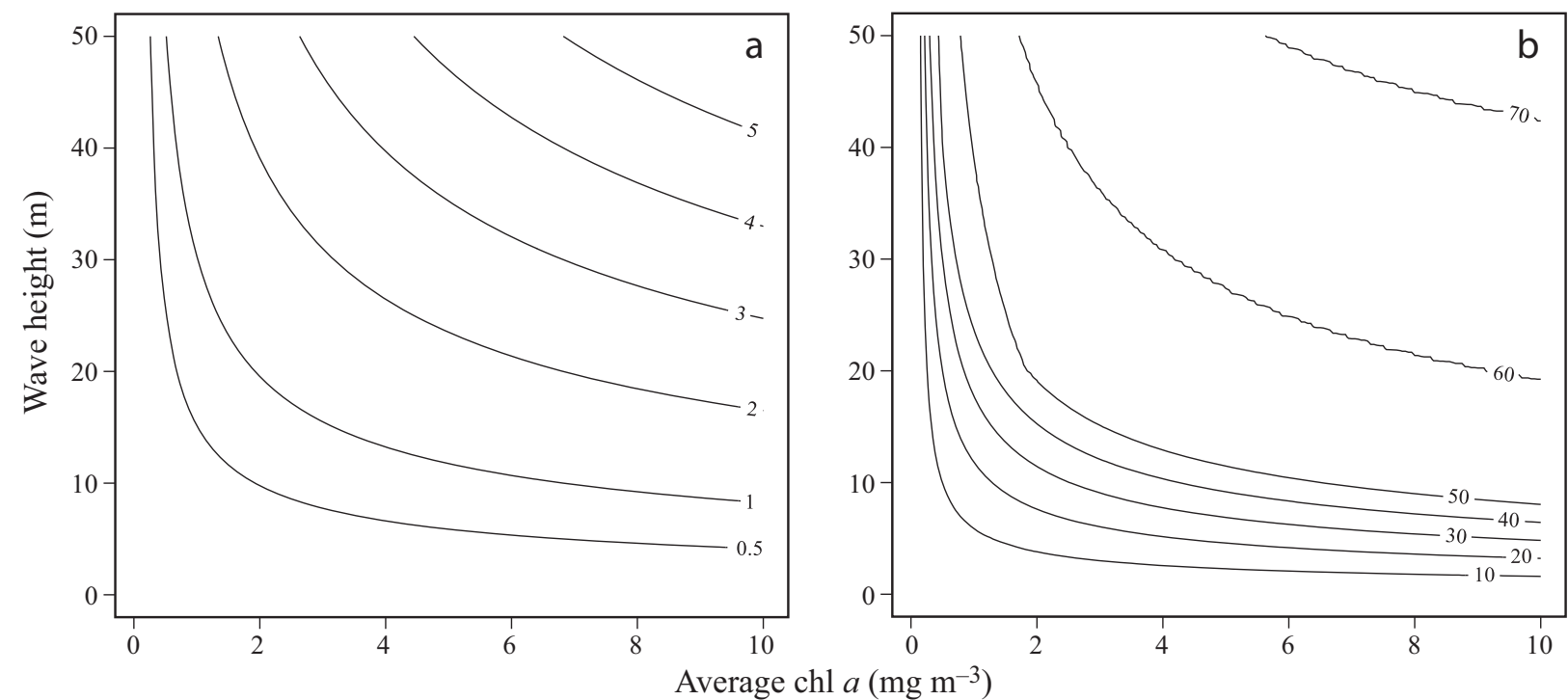

Fig. 7. Model calculation showing the combined effect of wave height and water chl a for light levels at depth. (a) The ratio $\left(\log _{10}\right)$ between maximum and minimum light intensities at $100 \mathrm{~m}$ depth with the passage of an internal wave. (b) The upward vertical displacement in meters of the isolume at $100 \mathrm{~m}$ depth with the passage of an internal wave

Marrase 1987) off the Namibian coast. If this value of $K$ is used instead of $0.21 \mathrm{~m}^{-1}$ for the upper $40 \mathrm{~m}$, a hypothetical reduction in irradiance of 7 to 8 orders of magnitude would have been the case for all depths below.

Our observations were made in the Benguela Current, one of the main upwelling and fish-producing regions of the world. The mechanisms revealed here should also apply to other productive regions. A simple model applying Eqs. (1) \& (2) (see 'Materials and methods') illustrates the combined influence of the height of the internal wave and the chl a concentration on the light conditions in deep waters. The model assumes a simple 2-layer system, with all of the chlorophyll confined to the upper layer. The upper layer depth prior to wave perturbation is set at $40 \mathrm{~m}$, with a $K$ of $0.045 \mathrm{~m}^{-1}$ applied for the water below (Fig. 7). The model suggests a strong relation with wave amplitude due to the exponential effect of light attenuation with increasing depth (Fig. 7). The fluctuation of light conditions at depth may reach several orders of magnitude, and isolumes move tens of meters even with relatively moderate upper-layer chl $a$ values when the wave height reaches 20 to $30 \mathrm{~m}$. Internal waves are ubiquitous in the oceans (Jackson 2004), with amplitudes of tens of meters commonly occurring (Warren et al. 2003), and the amplitudes sometimes reach 60 to $80 \mathrm{~m}$ (Osborne \& Burch 1980, Sandstrom \& Elliott 1984, Jackson 2004). Thus, fluctuating shading caused by internal wavemediated variations in the thickness of a turbid surface layer may be a general phenomenon in upwelling areas and on continental shelves. High trophic transfer efficiency has been assumed to explain the high fish production in the major upwelling systems (Ryther 1969). From our study, it can be hypothesized that FVM caused by internal waves contribute to such high trophic transfer efficiency.

Acknowledgements. We thank M. J. Gibbons for access to the catch data of fish and jellyfish. This study was supported by the National Research Foundation of South Africa, the Research Council of Norway, and our home institutions.

\section{LITERATURE CITED}

Axelsen BE, Krakstad JO, D'almeida D (2004) Aggregation dynamics and behaviour of the Cape horse mackerel (Trachurus trachurus capensis) in the Northern Benguela-implications for acoustic abundance estimates. In: Sumaila UR, Boyer D, Skogen MD, Steinshamn SI (eds) Namibia's fisheries: Ecological, economic and social aspects. Eburon, Delft

Baliño BM, Aksnes DL (1993) Winter distribution and migration of the sound-scattering layers, zooplankton and micronekton in Masfjorden, western Norway. Mar Ecol Prog Ser 102:35-50

Brierley AS, Axelsen BE, Buecher E, Sparks CAJ, Boyer H, Gibbons MJ (2001) Acoustic observations of jellyfish in the Namibian Benguela. Mar Ecol Prog Ser 210:55-66

Clark CW, Levy DA (1988) Diel vertical migration by juvenile sockeye salmon and the antipredation window. Am Nat 131:271-290

Engås A, Skeide R, West CW (1997) The 'MultiSampler': A system for remotely opening and closing multiple codends on a sampling trawl. Fish Res 29:295-298 
Estrada M, Marrase C (1987) Phytoplankton biomass and productivity off the Namibian Coast. S Afr J Mar Sci 5: 347-356

Garabato ACN, Polzin KL, King BA, Heywood KJ, Visbeck M (2004) Widespread intense turbulent mixing in the Southern Ocean. Science 303:210-213

Garrett C, Munk W (1979) Internal waves in the ocean. Annu Rev Fluid Mech 11:339-369

Giske J, Aksnes DL (1992) Ontogeny, season and tradeoffs-Vertical distribution of the mesopelagic fish Maurolicus Muelleri. Sarsia 77:253-261

Gliwicz MZ (1986) Predation and the evolution of vertical migration in zooplankton. Nature 320:746-748

Graham TR, Harvey JR, Benson SR, Renfree JS, Demer DA (2010) The acoustic identification and enumeration of scyphzoan jellyfish, the prey for leatherback sea turtles (Dermochelys coriacea), off central California. ICES J Mar Sci 67:1739-1748

Greenlaw CF (1979) Acoustical estimation of zooplankton populations. Limnol Oceanogr 24:226-242

- Haury LO, Briscoe MG, Orr MH (1979) Tidally generated internal wave packets in Massachusetts Bay. Nature 278: 312-317

Holligan PM, Pingree RD, Mardell GT (1985) Oceanic solitons, nutrient pulses and phytoplankton growth. Nature 314:348-350

Inthorn M, Mohrholz V, Zabel M (2006) Nepheloid layer distribution in the Benguela upwelling area offshore Namibia. Deep-Sea Res I 53:1423-1438

Jackson CR (2004) An atlas of internal solitary-like waves and their properties, 2nd edn. Global Ocean Associates, Alexandria, VA. Available at www.internalwaveatlas. com

Kaartvedt S, Melle W, Knutsen T, Skjoldal HR (1996) Vertical distribution of fish and krill beneath water of varying optical properties. Mar Ecol Prog Ser 136:51-58

Kaartvedt S, Klevjer TA, Torgersen T, Sørnes TA, Røstad A (2007) Diel vertical migration of individual jellyfish (Periphylla periphylla). Limnol Oceanogr 52:975-983

Kirk JTO (2011) Light and photosynthesis in aquatic ecosystems. Cambridge University Press, Cambridge

Lande R, Yentsch CS (1988) Internal waves, primary production and the compensation depth of marine phytoplankton. J Plankton Res 10:565-571

Ledwell JR, Montgomery ET, Polzin KL, St Laurent LC, Schmitt RW, Toole JM (2000) Evidence for enhanced mixing over rough topography in the abyssal ocean. Nature 403:179-182

Lennert-Cody CE, Franks PJS (1999) Plankton patchiness in high-frequency internal waves. Mar Ecol Prog Ser 186: 59-66

Longhurst AR, Pauly D (1987) Ecology of tropical oceans. Academic Press, San Diego, CA

Macias D, Somavilla R, González-Gordillo JI, Echevarria F (2010) Physical control of zooplankton distribution at the Strait of Gibraltar during an episode of internal wave

Editorial responsibility: Alejandro Gallego,

Aberdeen, UK generation. Mar Ecol Prog Ser 408:79-95

Morel A (1988) Optical modeling of the upper ocean in relation to its biogenous matter content (Case-I waters). J Geophys Res C 93:10749-10768

> Osborne AR, Burch TL (1980) Internal solitons in the Andaman Sea. Science 208:451-460

Pillar SC, Barange M (1995) Diel feeding periodicity, daily ration and vertical migration of juvenile Cape hake off the west coast of South African. J Fish Biol 47:753-768

Pillar SC, Barange M (1997) Diel variability in bottom trawl catches and feeding activity of the Cape hakes off the west coast of South Afric. S Afr J Mar Sci 54:485-499

> Pillar SC, Barange M (1998) Feeding habits, daily ration and vertical migration of the Cape horse mackerel off South Africa. S Afr J Mar Sci 19:263-274

R Development Core Team (2011). R: a language and environment for statistical computing. R Foundation for Statistical Computing, Vienna. Available at www.r-project. org

Ringelberg J (2010) Diel vertical migration of zooplankton in lakes and oceans. Springer, Dordrecht

Rosland R, Giske J (1994) A dynamic optimization model of the diel vertical-distribution of a pelagic planktivorous fish. Prog Oceanogr 34:1-43

Ryther JH (1969) Photosynthesis and fish production in the sea. Science 166:72-76

> Sandstrom H, Elliott JA (1984) Internal tides and solitons at the Scotian shelf: a nutrient pump at work. J Geophys Res C 89:6415-6426

Sassa C, Tsukamoto Y, Yamamoto K, Tokimura M (2010) Spatio-temporal distribution and biomass of Benthosema pterotum (Pisces: Myctophidae) in the shelf region of the East China Sea. Mar Ecol Prog Ser 407:227-241

Scheuerell MD, Schindler DE (2003) Diel vertical migration by juvenile sockeye salmon: Empirical evidence for the antipredation window. Ecology (USA) 84:1713-1720

Shroyer EL, Moum JN, Nash JD (2010) Mode 2 waves on the continental shelf: ephemeral components of the nonlinear internal wavefield. J Geophys Res C 115:C07001 doi:07010.01029/02009JC005605

> Staby A, Aksnes DL (2011) Follow the light-diurnal and seasonal variations in vertical distribution of the mesopelagic fish Maurolicus muelleri. Mar Ecol Prog Ser 422: 265-273

Utne-Palm AC, Salvanes AGV, Currie B, Kaartvedt S and others (2010) Trophic structure and community stability in an overfished ecosystem. Science 329:333-336

> van der Bank MG, Utne-Palm AC, Pittman K, Sweetman AK, Richoux NB, Brüchert V, Gibbons MJ (2011) Dietary success of a 'new' key fish in an overfished ecosystem: evidence from fatty acid and stable isotope signatures. Mar Ecol Prog Ser 428:219-233

> Warren JD, Stanton TK, Wiebe PH, Seim HE (2003) Inference of biological and physical parameters in an internal wave using multiple-frequency, acoustic scattering data. ICES J Mar Sci 60:1033-1046

Submitted: September 1, 2011; Accepted: February 22, 2012 Proofs received from author(s): March 21, 2012 